10-1-2021

\title{
Identifying factors that support community health worker motivation, job satisfaction, and retention in Haiti
}

Frontline Health Project

Johns Hopkins Bloomberg School of Public Health

Follow this and additional works at: https://knowledgecommons.popcouncil.org/departments_sbsr-rh

Part of the Health Services Research Commons, and the Public Health Education and Promotion Commons

How does access to this work benefit you? Let us know!

\section{Recommended Citation}

Frontline Health Project and Johns Hopkins Bloomberg School of Public Health. 2021. "Identifying factors that support community health worker motivation, job satisfaction, and retention in Haiti," Results brief. Washington, DC: Population Council. 


\section{Identifying Factors that Support Community Health Worker Motivation, Job Satisfaction, and Retention in Haiti}

\section{INTRODUCTION}

Community health workers (CHWs) play a critical role in Haiti's health system, by connecting communities-particularly rural and hard-to-reach populations - to healthcare services (1). CHWs are often the only point of contact communities have with health systems. In Haiti, CHWs are organized under one cadre: the Agents de Santé Communautaire Polyvalent (ASCP; 'Polyvalent Community Health Workers'). ASCPs provide a variety of health services to communities through clinical services, health education, and community mobilization. These responsibilities cover maternal and child health services, family planning, nutrition, counseling, and infectious disease services $(1,2)$.

Haiti's Ministry of Public Health and Population (MSPP) formalized the ASCP program in 2015, which consolidated several CHW cadres into one cadre of ASCPs, standardizing services and the training curriculum in the process $(2,3)$ the need for daily, long-term adherence to medication for HIV and TB was initially the driving factor for recruitment of CHWs. Haiti's CHW program is primarily funded by donors (2). ASCPs are employed by both MSPP as well as local partnering organizations (e.g., Zanmi Lasante). ASCPs operate as a part of an Équipes de Santé de la Famille (ESF; ' Family Health Teams'), which are teams comprising of 60 ASCPs, auxiliary nurses, and doctors with each ESF team serving around 60,000 people (4).

Since 2014, Haiti's CHW program has faced a worker shortage with only 3,161 ASCPs working, compared to the recommended 10,920 ASCPs (2). Furthermore, a 2010 study in Haiti documented that CHWs faced many challenges that have impacted their motivation to conduct their work including: inadequate supplies and equipment (i.e., umbrellas, medicines), lack of transportation and identity badges, late payments, and high workloads (3) the need for daily, long-term adherence to medication for HIV and TB was initially the driving factor for recruitment of $\mathrm{CHWs}$. The World Health Organization has recommended a combination of both monetary and non-monetary incentives for $\mathrm{CHWs}$ to support $\mathrm{CHW}$ motivation, performance, and retention (5).

The Frontline Health project conducted a study to better understand the types of incentive structures that can best support ASCPs in Haiti. The study was conducted through a collabora-

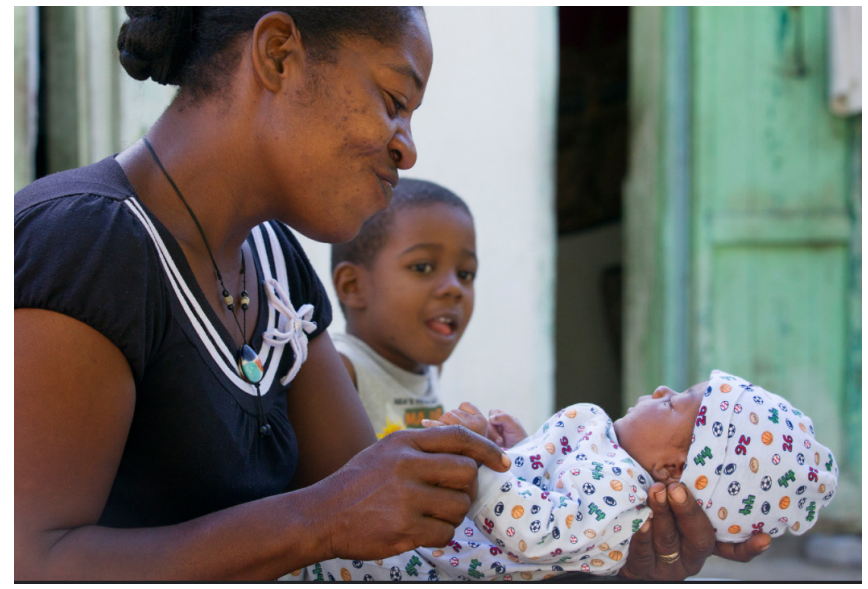

Photo: Mike DuBose

\section{KEY FINDINGS}

1. Low compensation for salaries and transportation were found to discourage ASCPs from performing job activities. Increased and timely payments are essential for improving job motivation.

2. Communities strongly value ASCPs work therefore credibility must continue to be improved (e.g. improved referral pathways).

3. Work recognition was reported as an important way for ASCPs to recognize their impacts on improving health outcomes. 
tion with the Population Council, the Johns Hopkins Bloomberg School of Public Health, Zanmi Lasante, USAID, and UNICEF, and was supported by the Bill \& Melinda Gates Foundation.

\section{METHODOLOGY}

This study investigated factors influencing ASCP motivation, job satisfaction, and their preferences for financial and non-financial incentives. Focus group discussions (FGDs) were held with ASCPs and ASCP supervisors in Haiti's Lascahobas, Mirebalais, Petite Rivière de l'Artibonite (PRA), and Verrettes communes (see Figure 1). Participants primarily included respondents from Zanmi Lasante as well as Albert Schweizer Hospital. FGDs were held in September and December 2019, and January 2020. Due to ongoing political conflicts in Haiti, data collection was staggered to ensure that participants and data collectors were not put at risk. FGDs centered on the types of incentives and disincentives that support or inhibit ASCP motivation, job satisfaction, retention, ASCPs relationships with communities and healthcare facilities, and perspectives on policy-level commitment towards the ASCP program. In total, 66 participants took part in this study through five FGDs that were held with 30 ASCPs, and six FGDs with 36 ASCP supervisors (see Table 1).

TABLE 1. NUMBER OF FGD PARTICIPANTS, BY COMMUNE

\begin{tabular}{|l|c|c|c|}
\hline Location & $\begin{array}{c}\text { No. CHW } \\
\text { FGD } \\
\text { participants }\end{array}$ & $\begin{array}{c}\text { No. CHW } \\
\text { Supervisor } \\
\text { FGD } \\
\text { participants }\end{array}$ & Total \\
\hline Verrettes* & 12 & 12 & 24 \\
\hline Lascahobas & 6 & 6 & 12 \\
\hline Mirebalais & 12 & 12 & 24 \\
\hline $\begin{array}{l}\text { Petite Riviere } \\
\text { de l'Artibonite }\end{array}$ & 0 & 6 & 6 \\
\hline Total & 30 & 36 & 66 \\
\hline $\begin{array}{l}\text { *Verrettes also included ASCPs and ASCP supervisors from } \\
\text { Albert Schweizer Hospital, in addition to Zanmi Lasante } \\
\text { respondents. }\end{array}$
\end{tabular}

Figure 1: FGDs and IDIs were conducted in five communes in Haiti, indicated on the map.

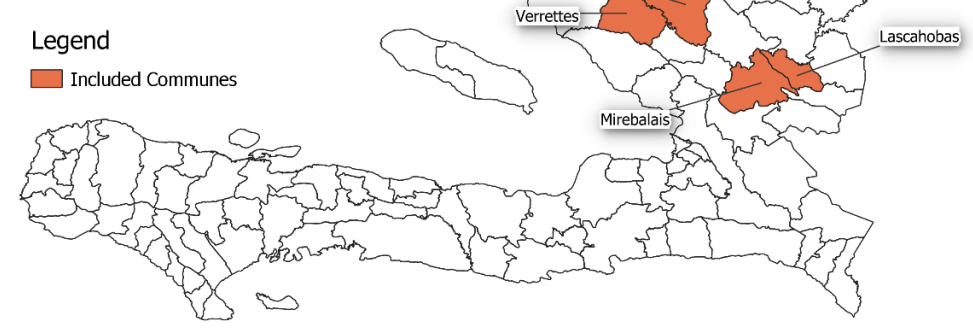

\section{RESULTS}

\section{MONETARY INCENTIVES}

\section{ASCPs require improvements and parity in pay structures, as salaries are currently insufficient considering ASCPs' workloads.}

Salary: ASCPs are salaried, receiving around 12,100 Haitian Gourdes (HTGs) (USD \$160) monthly (4). ASCPs do not universally receive the same salary as compensation is dependent upon an ASCP's primary organization's monetary capacity (6). Additionally, salaries are sometimes reduced to $11,000-11,600$ HTG (USD \$142-\$150) depending on ASCPs' training levels (6). Overall, ASCPs believe salary amounts provided thus far have been insufficient in covering their work-related costs and basic needs. Given the increasing workloads, ASCPs desire raises.

\footnotetext{
"Well, I think for the work we are doing, if the salary were increased, it would be better because the salary is a bit minimal [...] it will make us happy. Even when they would increase the burden, we will always be willing to work." - $A S C P$
}

Furthermore, ASCPs found delayed payments demotivating: "This month we work, we didn't get paid until next month, and when they paid me, I am discouraged." ASCPs also discussed the importance of parity, noting that ASCPs should all receive equal pay:

"That means if, for example, one is being paid $20,000 \mathrm{HTG}$ and the other is getting $25,000 \mathrm{HTG}$, we should be encouraged by having equal pays [...] because we would know we are all treated the same." $-A S C P$ 
Transportation Allowance: ASCPs often have to cover work-related travel costs themselves due to insufficient transportation allowances. One ASCP supervisor noted that transportation allowances were larger in the past. ASCPs also shared that being unable to afford travel expenses affected their performance: "Sometimes, if the person does not have the money, he cannot come. The distance from the area to go pick up the vaccine then to get back... it is their funds that also support the cost of doing so," (ASCP Supervisor).

Bonuses and Other Monetary Incentives: ASCPS reported receiving bonuses infrequently. ASCPs discussed the importance of receiving incentives similar to those of other departments, citing how other departments have received bonuses and subsidies (allocations to support school-related fees for family members). A lack of incentives was viewed as demoralizing for ASCPs.

"There are sometimes things that come up that we will learn of elsewhere. The administration does not inform us. When you start doing followup about those things, that's when they tell you about it. Take, for example, the school grant, which we know of from other sites and institutions. The administration kept it from us. We never knew about it." - ASCP Supervisor

\section{NON-MONETARY INCENTIVES}

\section{ASCPs identified a range of non-monetary incentives that would support their motivation and job satisfaction, including transportation methods, recognition, among others.}

Service Contracts: Service contracts are a type of consultancy contract where the employee only pays $2 \%$ in taxes (7). These contracts are related to employment status, and impact the benefits ASCPs can receive-namely through receiving bank loans and a larger net salary (7). ASCPs noted that they had not signed service contracts in many months. ASCPs also desired copies of their signed contracts to indicate that they are employed; as a means of bolstering credibility in communities. "It has been a long time since we signed a 3-month contract. We haven't done that in a long time. True, we work, but we may be told that we are not recognized because we do not have a piece of paper in our hand." (ASCP Supervisor).

Means of Transport: Having consistent means of transportation is essential to ASCPs as carrying supplies over long distances has proven to be burden- some when reaching communities by foot. "I personally, climb many mountains. Access is difficult. If we could afford a motorcycle ride, even if it were a horse or a mule, it would be important," (ASCP). Some ASCPs mentioned that coordinating transportation plans pose a challenge to ASCPs who share motorcycles. "When we are given a motorcycle for two supervisors to share [...] there are many strategies we do to ensure that we do not need to go on opposite directions on a given day," (ASCP Supervisor).

Identification: Forms of identification (e.g., badges) facilitate trusting relationship by allowing ASCPs' to better represent themselves. Without identification, ASCPs shared it was difficult to assert their credibility with health facility staff or in communities. "If I were to go to an institution, no one would know I was working at...because I don't have a badge," (ASCP).

It is important to ensure that ASCPs are provided with adequate tools and supplies. Their lack of supplies undermines their ability to work effectively and can harm their relationships with communities.

Availability of Supplies: ASCPs reported difficulty obtaining a range of tools required for their work, including vaccines and their distribution supplies (e.g., syringes, freezers). Repairs or replacements of existing tools was also of critical concern, with ASCPs referencing broken freezers not being replaced. ASCPs also requested sufficient quantities of tools such as medicines and registers to improve work effeciency. "For 3 months now, we have not been able to get vaccines. [...] The nurse made the request - the vaccine was given but we did not find the accompanying materials, supplies such as syringes," (ASCP).

Training: ASCPs shared that trainings were useful and that they were being provided training, though some reported logistical issues with certifications or receiving all training modules: "The encouragement I think I would get would be to get all the training modules. We only completed one module so far...," (ASCP). ASCPs reported feeling well equipped to identify health problems and address community needs.

Recognition: Recognition of ASCPs; role and other healthcare workers' willingness to collaborate with ASCPs was viewed as a work motivator. Recognitionboth tangible (e.g., certificates, plaques) and intangible (e.g., providing gratitude and credit to ASCPs)from communities, supervisors, organizations, or other leaders was appreciated. The level and amount 
of recognition can vary. "Of the 3 community center nurses past, [two] gave me a plaque. [...] And last year, they gave me another one," (ASCP Supervisor). Some ASCPs are no longer receiving incentives in the form of plaques, noting that its return would be encouraging. ASCPs also reported that a significant motivating factor was their ability to support community members and see the impact of their work on improving health outcomes. "But I am saving lives, I continue on the same momentum, I am not discouraged," (ASCP Supervisor).

Relationship with Communities: Communities and ASCPs share a strong relationship; ASCPs' advice and assistance are valued, and community members actively seek out ASCPs for their services (e.g., vaccinations). This relationship is paramount as it simultaneously provides encouragement and recognition for ASCPs, which can support their performance and retention. "First it would be the support that I am given [...] that can allow me to go and do activities on the ground better," (ASCP).

Relationship with Health Facilities: ASCPs shared that communication and collaborative support from healthcare facility staff was encouraging and fruitful. However, referrals were not consistently honored by facility staff which harmed their credibility with communities. "What discourages me is when you make a referral for a pregnant woman, when they arrive, they are not so well received. When the person returns, they are a bit cross with you," (ASCP).

Referrals: ASCPs reported that referral forms were not always available to ASCPs. Additionally, in cases where patients were successfully referred, facility staff did not provide counter-referrals which enable ASCPs to continue to monitor their patients at the community-level (7). This has resulted in some ASCPs forgoing the referral process altogether (7).

Workloads: Burgeoning workloads coupled with other demotivating factors have frustrated ASCPS. ASCPs are poorly equipped to handle large populations due to the lack of manpower and sheer extent of their work. Increased recruitment is essential. "The state gives me only 60 doses of pentavalent vaccine. And yet, I have 500 children in my population to vaccinate [...] You see, we do forced labor too, because we work on more population than we have the means to do," (ASCP Supervisor).

\section{CONCLUSION}

ASCPs are intrinsically motivated to support their communities, but are often constrained by many challenges that can negatively impact their motivation, job satisfaction, and performance. Despite Haiti's CHW program taking steps towards improving the community health system, further changes must be made to improve ASCP working conditions. This study identified a range of potential non-monetary and monetary incentives relevant to ASCPs that can better support them as they continue to ameliorate community health outcomes.

\section{RESEARCHER CONTACTS}

Smisha Agarwal

Assistant Professor, Department of International Health

The Johns Hopkins Bloomberg School of Public Health sagarw23@jhu.edu

\section{Alain Casseus}

Zanmi Lasante, Haiti

acasseus@pih.org

Pooja Sripad

Population Council

psripad@popcouncil.org

Suggested citation: Frontline Health Project and Johns Hopkins Bloomberg School of Public Health. 2021. Identifying Factors that Support Community Health Worker Motivation, Job Satisfaction, and Retention in Haiti. Washington, D.C.: Population Council.

\section{REFERENCES}

1. Documents MSPP d' organisation de soins de sante communautaire.

2. Partners A. Community Health Systems Catalog Country Profile: Haiti - September 2016. 2016.

3. Jerome G, Ivers LC. Community health workers in health systems strengthening: A qualitative evaluation from rural Haiti. Aids [Internet]. 2010 Jan [cited 2020 Sep 15];24(SUPPL. 1):S67. Available from: https://pubmed.ncbi.nlm.nih.gov/20023442/

4. Community Health Roadmap. Haiti Community Health Roadmap [Internet]. 2019 [cited 2021 Feb 23]. Available from: https://static1.squarespace.com/static/5bb6ac499d4149304f7ef3f5/t/5d77475c35908f70af4b6d75/1568098147647/Haiti-20190909-1.pdf

5. World Health Organization. WHO Guideline on health policy and system support to optimize community health worker programmes. Geneva, Switzerland; 2018.

6. Casseus A. Personal Communication. 2021.

7. Isaac B. Personal Communication. 2021. 